\title{
Editorial
}

Dennis R. Young*

\section{Editor's Note: Volume 5, Issue 1}

*Corresponding author: Dennis R. Young, Georgia State University, Atlanta, GA, USA, E-mail: dennisryoung@gsu.edu

I am pleased to introduce this especially robust first issue of 2014. The flow of fine manuscripts to Nonprofit Policy Forum is growing so we are led to put forward this issue with seven full articles and, as our Feature, a thoughtful essay reviewing an important new book.

Consistent with our philosophy of learning from all parts of the world, this issue is strongly international in content. We begin the set of regular articles with a timely and significant paper on the proposed new statute governing cross-border charitable activity in the European Union, and we conclude with analyses of volunteering policy in China and the restructuring of fiscal relations between civil society organizations and government in France. On the inside of this global sandwich, we offer four papers on various policy topics affecting nonprofit organizations in the United States.

Oonagh Breen's trenchant and timely analysis of the European Commission's proposal for a Council Regulation for a European Foundation Statute examines the multiple dimensions of strengthening cross-border charitable activity within the European Union, and how the proposed new construct of a supranational legal form interfaces with the regulatory and taxation regimes of member countries. This is a major issue in Europe where most of its 110,000 foundations engage in international activity. Breen identifies the challenges of standardization across countries and the missed opportunities and loopholes that improvements in the current draft statute should address in order to enhance the transparency, accountability, uniformity, effectiveness, and efficiency of regulation of charitable organizations that operate across European borders. This article is clearly must reading for policy makers and scholars in Europe, but also for scholars and policymakers elsewhere, as charitable and philanthropic activity becomes increasingly global in character.

In the second article, John Brennan, Laurie Paarlberg, and Michele Hoyman examine the impact of nonprofits on economic development in 360 cities in the 
United States. While there are various theories about how nonprofits may contribute to economic development through production of services, support of creativity and innovation, and building of social capital, solid evidence is lacking. The importance of this article is to provide a rigorous empirical assessment of these claims and set the stage for more incisive research. Given the diversity of nonprofits themselves, and the locales in which they operate, it is perhaps unsurprising that the results are mixed at best. Some types of nonprofits appear to enhance economic growth while other types may detract from it. The processes are complex, involving individual behaviors, diverse organizational structures, and varying contexts. No clear argument emerges for investing in nonprofits to achieve economic growth, nor any magic bullet for how to do so. However, this analysis points to a rich research agenda for pinpointing where nonprofits may be helpful in the local economic development process.

The third paper by Brent Never studies the fiscal health of human service nonprofits affected by cutbacks in funding for human services in the past decade. Nonprofit organizations are subject to fiscal stresses in much the same way that businesses are. The paper is innovative in its methodology joining tax form 990 data on nonprofits from the National Center for Charitable Statistics with data from the American Community Survey to study the spatial as well as economic and organizational factors influencing fiscal stress. Never applies fiscal stress tests customized to nonprofits to determine which human service nonprofits have faced particular difficulties in the recent turbulent economic environment. He finds that the cuts in human services funding are especially hurting those organizations serving minority communities. The results have potentially important implications for the structure of public funding of human services in the United States where devolution of funding programs has left minority communities especially vulnerable.

The fourth paper, by Heath Brown, is set in the context of US foundations' involvement in public policy. Brown notes that US foundations have been significantly involved in shaping public policy in the United States for the last century and have moved to the center of policy debates over the past fifty years. In this paper, Brown is concerned with US nonprofits that serve the needs of immigrants, with voter registration and other matters. He finds that these nonprofits operate in a decidedly conflicted philanthropic community, helped by some foundations that pro-actively support their efforts and hindered by other foundations, hostile to illegal immigration, which fund nonprofits with opposing viewpoints. Looking past the present debate on immigration reform, Brown questions how well nonprofits can continue to support the needs of immigrant communities if future policy priorities of foundations change. 
The fifth paper by Margaret Sloan is again concerned with financial impacts of government policy on nonprofits. Sloan takes a careful look at the state government affiliates of the federal White House Office of FaithBased and Neighborhood Partnerships which were intended, in part, to increase states' effectiveness in attracting federal funding to their faithbased and community organizations. While analysis of a statistical regression model of the determinants of federal grant funding finds that indicators of local need and the density of local nonprofits have significant impacts on funding, no discernible impact is found for the presence of the state affiliates, calling into question one of the premises behind the initiative to expand social service capacity through state-linked support of faith-based and community organizations. A further qualitative survey of the affiliate state offices identifies a number of possible factors explaining their apparent ineffectiveness, including a dearth of financial and staff resources devoted to the state affiliates, poor communications between the states' and federal program offices, and weak commitment and changing priorities in governors' offices. These are generic issues that may have broader implications for state strategies for securing federal resources in other contexts.

In the sixth paper, Ying Xu explores some of the nuances of volunteering in China, a country in transition where government remains in tight control of nonprofit organizations but where circumstances are changing. In this context, spontaneous volunteer participation in grassroots organizations co-exists with compulsory volunteering in top-down programs. Xu's study focuses on the city of Jinan where she finds clear differences between the two types of volunteering in the attitudes and prospective contributions of volunteers to Chinese civil society. In particular, $\mathrm{Xu}$ highlights the value of a rewarding volunteering experience, more likely to be found in spontaneous volunteering. The results suggest the relevance of seeking to improve relations and communications between government and grassroots organizations and exploring possible government support for spontaneous volunteering.

In the final article by Damien Mourey, Philippe Eynaud, and Carolyn Cordery, we return to Europe - France in particular. Again the issue is the funding relationship between nonprofits and government, and how changes in this relationship affect civil society more broadly. Through a case study of one CSO that is heavily funded by government, serving migrants in an urban area, the authors examine the recent upheaval in France from a regime of collaborative grant making to a narrower one of government procurement contracting for specific services. The authors document the impacts of this change on what they characterize as the "three pillars" of CSO operation - mission, values, and funding. The effect, they observe, is to alter how CSOs now function in the 
public sphere. In particular, they find that the nonprofit-government relationship has changed from a generally cooperative one to an adversarial one, jeopardizing CSOs' wider contributions to the social and economic health of the community, and forcing them to forge new financial and social relationships and organizational strategies.

In our Feature section, Patricia Rosenfield and Rachel Wimpee's essay reviews an important new book on American foundations by David C. Hammack and Helmut K. Anheier, A Versatile American Institution: The Changing Ideals and Realities of Philanthropic Foundations. Rosenfield and Wimpee find this book to be a very significant contribution to our understanding of American grant making foundations in the United States since colonial times. In particular, the book elucidates contemporary influences of these foundations on American public policy, foundations' roles in helping to finance public services, and the response of foundations to political pressures for more stringent regulation of their activities. Moreover, the reviewers highlight the insights this book provides into future strategy of foundations, including the need to build and strengthen partnerships in order to leverage their relatively limited resources. Rosenfield and Wimpee also enhance these insights with perspectives of their own, giving us a glimpse into the future of the foundation world, including the emergence of mega-foundations, a new boldness in foundation engagement in policy advocacy, and the growth of global grant making and international philanthropy.

In all, the papers in this issue continue to clearly demonstrate the growing and complex interconnections between the nonprofit sector and public policy, across the globe and in the many different fields in which nonprofit institutions contribute to public welfare. I hope you enjoy the issue and find it worthy of our goal to bring rigorous research-based knowledge to bear on the important policy issues addressed here by our authors. 